\title{
¿MAGONIA O MAONIA? SOBRE LOS ORÍGENES DEL NOMBRE DE UNA TIERRA MÍTICA
}

\author{
MAGONIA OR MAONIA? \\ ON THE ORIGINS OF THE NAME OF A MYTHIC LAND
}

\author{
Juan Antonio JimÉNEZ SÁNCHEZ* \\ Universidad de Barcelona
}

\begin{abstract}
RESUMEN. El presente trabajo pretende estudiar el origen del nombre de Magonia, un topónimo que, pese a su gran popularidad, corresponde a un hápax que solo se documenta en una obra de Agobardo de Lyon, aunque una glosa de Floro a un escrito de Agustín nos ofrece la variante Maonia. A fin de vislumbrar el origen de esta palabra, analizaremos los textos francos de los siglos viI y viII que hacen alusión a los maones - los ladrones de cosechas por medios mágicos-, examinaremos las propuestas de la historiografía contemporánea y finalmente ofreceremos nuestra propia hipótesis: el nombre de Magonia procede de Hemonia (Tesalia), aunque posteriormente perdió el componente toponímico y lo recuperó en el siglo IX con Agobardo, quien creó la forma Magonia para hacer referencia a un lugar que ya nada tenía que ver con la realidad.
\end{abstract}

PALABRAS CLAVE. Agobardo de Lyon, Floro, maones, tempestarios, magia, tormentas.

ABSTRACT. The present work aims to study the origin of the name of Magonia, a place name that, despite its great popularity, corresponds to a hapax only documented in a Agobard of Lyon's work, although a Florus' gloss to Augustine offers the variant Maonia. In order to find the origin of this word, we will analyze 7th and 8th centuries Frankish texts which allude to the maones - harvest thieves who made use of magical means-, we will examine the proposals of contemporary historiography, and finally we will offer our own hypothesis: the name of Magonia comes from Hemonia (Thessaly), even though it lost the toponymic component and recovered it in the 9th century with Agobard, who created the form Magonia to refer to a place that no longer had anything to do with reality.

KEYWORDS. Agobard of Lyon, Florus, maones, tempestarii, magic, storms.

\footnotetext{
* Correspondencia a / Correspondence to: Juan Antonio Jiménez Sánchez, Universidad de Barcelona (Facultad de Geografía e Historia), C/ Montalegre, 6 (08001 Barcelona) - jjimenez@ub.edu - https://orcid.org/0000-0002-7382-1278.

Cómo citar / How to cite: Jiménez Sánchez, Juan Antonio (2021), "¿Magonia o Maonia? Sobre los orígenes del nombre de una tierra mítica», Veleia, 38, 239-249. (https://doi.org/10.1387/veleia.21843).
}

Recibido: 25 junio 2020; aceptado: 6 noviembre 2020.

ISSN 0213-2095 - elSSN 2444-3565 / (C) 2021 UPV/EHU 
El nombre de Magonia, el mítico país del que arribaban unos barcos voladores cuyos aeronautas se llevaban los frutos caídos por la acción del granizo, ha devenido extraordinariamente célebre en los últimos siglos, especialmente entre los ufólogos del siglo xx, quienes lo han citado de manera incansable como un ejemplo de avistamientos de ovnis en tiempos medievales. Sin embargo, este nombre tan repetido corresponde en realidad a un hápax que tan solo documentamos en Agobardo de Lyon, quien lo cita en una única ocasión en su De grandine et tonitruis (escrito ca. 816). A partir del descubrimiento de las obras de Agobardo en 1605, el topónimo fue ganando en importancia hasta el punto de que el afamado ufólogo Jacques Vallée tituló su obra más conocida como Passport to Magonia: From Folklore to Flying Saucers (1969); además, una de las revistas más conocidas sobre el tema también se llama Magonia1. Floro de Lyon (siglo Ix) recogió asimismo el nombre de esta tierra en un escolio a una obra de Agustín de Hipona, aunque en esta ocasión el diácono lionés denominó Maonia a esta tierra así como llamó maones a sus habitantes -Agobardo, en cambio, solo aludió al nombre de la tierra, pero jamás al de sus habitantes, que por lógica deberían ser «magonios»-.

Estas diferencias nos llevan a plantearnos cuál fue el nombre originario de este lugar y cómo llegó a gestarse dicho topónimo, unas cuestiones a las que, en la medida de lo posible, pretendemos ofrecer una respuesta en las presentes páginas. Para ello, nos remontaremos a algunos testimonios francos de los siglos viI y viII, en los que, con ligeras variantes, también se alude a los maones; seguidamente, revisaremos la opinión de la historiografía contemporánea al respecto; y acabaremos nuestro estudio exponiendo nuestra hipótesis: el nombre de Magonia tuvo su remoto origen en Hemonia —uno de los nombres de Tesalia—; posteriormente, perdió su carácter de topónimo y el antiguo gentilicio (hemaones) persistió, con las lógicas diferencias dialectales, aunque ya no como un gentilicio, sino como una alusión a una categoría de delincuentes que se servían de la magia para robar las cosechas ajenas; finalmente, al identificarse a estos magos con gentes venidas de otra tierra, se recuperó la idea del topónimo para crear un nombre de nuevo cuño, Magonia o «Tierra de los magos».

\section{LAS FUentes SOBRE LOS MAONES}

Este primer apartado ha de poseer necesariamente un carácter descriptivo. En él repasaremos por orden cronológico las diversas fuentes — pocas, ciertamente- que hablaron de los maones entre los siglos VII y IX. Todas ellas se enmarcan en la mitad oriental del Reino Franco; y, dado que no contamos con alusiones a tales personajes fuera de esta zona, hemos de presuponer que nos hallamos ante una terminología restringida a estos territorios.

El primer testimonio lo documentamos en la Vita Richarii primigenia, la más antigua de las biografías que conservamos sobre Ricario, el fundador del monasterio de Centula (actual abadía de San Ricario, en Picardía) ca. 625. Según Albert Poncelet (1903, 184), la redacción de esta uita habría que situarla a finales del siglo vir. En su segundo capítulo, el anónimo autor nos narra la conversión al cristianismo de Ricario gracias a la predicación de Ficor y Caidoc, dos misioneros irlandeses que habían acudido a evangelizar el condado de Ponthieu. Sin embargo, una vez allí fueron

1 Aquí cabe decir igualmente que muchos de los que hablan sobre Magonia lo hacen más sobre el testimonio fantasioso de Le Comte de Gabalis, escrito en 1670 por
Montfaucon de Villars, que no por consultar directamente la obra de Agobardo. 
acogidos de manera hostil por los habitantes del territorio, quienes los acusaron de ser dusi -nombre con el que designaban a los brujos ${ }^{2}-\mathrm{y}$ hemaones. Se salvaron de la agresión de los lugareños tan solo gracias a la oportuna intervención del joven Ricario.

Fichori ex Hibernia et Chaidocus ex Scottorum patria ueniebant Siccambriam. Vir beatus Richarius fuit eorum obuius, ubi gentiles Pontearii inridebant ei: malefacere adfirmabant stulti, quod essent dusi; hemaones uocitabant, qui Deum non credebant; eis reputabant, quod segetes tollebant. $^{3}$

Como vemos, aquí aparece el nombre de hemaones asociado al robo de cosechas. Dicha asociación se ve confirmada en otras fuentes de la siguiente centuria.

La primera de ellas corresponde a Pirminio, monje misionero activo durante la primera mitad del siglo viIr. Su patria nos resulta desconocida, y aunque se han apuntado diversos orígenes, entre los que cabe destacar el hispano (en este sentido véase Andrés Sanz 2010, 265), no hay nada concluyente al respecto, y estudios recientes apuntan a que tal vez fuera un frisón de la zona de Frisia en el bajo Mosa (Hauswald 2010, XI). Su única obra conservada es el Scarapsus, un tratado catequético y dogmático destinado a la instrucción de la población cristiana. No se puede afirmar con seguridad dónde y cuándo lo redactó, aunque determinados elementos internos relacionados con las fuentes utilizadas en su elaboración han permitido a su máximo estudioso, Eckhard Hauswald, fijar su composición en el segundo cuarto del siglo viII (es decir, entre el 725 y el 750) (Hauswald 2010, XXI-XXII). En cuanto a su lugar de origen, aunque resulte difícil igualmente precisarlo, si aceptamos esta cronología, coincide con el período de estancia de Pirminio en Hornbach (en la década de los cuarenta del siglo viII). La tradición literaria y determinadas consideraciones lingüísticas - como precisamente el uso del término maones — lo vinculan con el noreste del Reino franco, más precisamente con la región de la Picardía (Hauswald 2010, XXII-XXIV) ${ }^{4}$.

En el capítulo 22, Pirminio censuraba algunas de las costumbres que los cristianos de su tiempo habían heredado de sus ancestros paganos. Entre ellas, se contaba la creencia en los tempestarios, individuos capaces de provocar tormentas con su sola voluntad. Pirminio también pedía a los fieles que no dieran nada a aquellos que aseguraban que los maones podían llevarse los frutos de la cosecha - y que, en consecuencia, a cambio de un pago podían evitar que los robaran-.

Tempestarius nolite credere; nec aliquid pro oc eis dare, qui dicunt, quod maones fructa tollere possent. $^{5}$

Como vemos, el vocablo maones sigue relacionado con los ladrones de frutos. Aunque está claramente relacionado con los hemaones de la Vita Richarii primigenia, el término ha sufrido una afé-

2 La palabra dusius era utilizada en territorio galo para referirse a un tipo de demonios que buscaban satisfacer sus pasiones cohabitando carnalmente con las mujeres; en este sentido podemos recordar: Augustinus, $D e$ ciu. Dei, XV, 23, 1 [p. 489]: et quosdam daemones, quos Dusios Galli nuncupant, hanc adsidue inmunditiam et temptare et efficere, plures talesque adseuerant, ut hoc negare inpudentiae uideatur; Isidorus, Etym., VIII, 11, 103 [s.p.]: saepe enim inprobi existunt etiam mulieribus, et ea- rum peragunt concubitum: quos daemones Galli Dusios uocant, quia adsidue hanc peragunt inmunditiam. Véase Du Cange 1884, 219-220.

3 Vit. Richar. prim., 2 [p. 445].

${ }^{4}$ Por tanto, disentimos de la afirmación de María Adelaida Andrés Sanz (2010, 265): «probablemente lo escribió antes de salir de la Península».

5 Pirminius, Scaraps., 22 [pp. 76-77]. 
resis de la vocal inicial, tal vez por la propia evolución de la palabra o tal vez por una simple diferencia dialectal.

También documentamos este término con ligeras diferencias en el otro testimonio del siglo viII. Se trata de un sermón anónimo que todavía no ha sido editado en su totalidad. Fue publicado de manera parcial por Wilhelm Levison en 1946 (Levison 1946, 302-314), aunque su editor no le otorgó ningún título; el mismo texto fue recogido y publicado por Adalbert Hamman en el volumen IV de la Patrologiae Latinae Supplementum bajo el título Sermo seu instructio rusticorum. El texto ha llegado hasta nosotros a través de tres manuscritos: a) B. M. Cotton Nero A II (copiado en el 778), que lo reproduce de manera incompleta en f. 14-45; b) Ms n. ${ }^{\circ} 94$ de la Zentralbibliothek de Zürich (anteriormente C 64) (escrito ca. 800), que lo reproduce de forma completa en f. 8-19 bajo el título Excarpsum de diuersis auctoribus; c) B. M. Arundel 213 (copiado en el primer tercio del siglo Ix), que lo transmite de manera fragmentaria en los f. 1-4 (Levison 1946, 303-305; Judic 1998, 23). Resulta imposible precisar el lugar de origen de este texto; por cuanto concierne a su fecha, el manuscrito B. M. Cotton Nero A II nos proporciona su terminus ante quem: habría sido elaborado antes del 778.

En un pasaje de este sermón, el anónimo predicador ruega a sus oyentes que no crean en los manones, de los que se dice que pueden robar las cosechas, ya que se trata de una superstición heredada de los paganos que cualquiera en su sano juicio rechazaría sin dudarlo.

(...) et mauonis, quasi messis et uindemia portari possint, quod hoc omnino non est credendum, quia hoc sapientes refutant et omnino menime credunt, quia hoc de paganorum consuetudine remansit. ${ }^{6}$

En este caso, la variante dialectal corresponde a manones, pero el sentido continúa siendo el mismo: ladrones de cosechas por medios mágicos.

Y llegamos de este modo al siglo Ix, donde encontramos al más célebre testimonio acerca de este tema, Agobardo de Lyon, quien redactó su célebre De grandine et tonitruis, su primera obra, ca. 8167. En el capítulo 2 de este tratado, el prelado lionés nos informa sobre la creencia de sus feligreses en una tierra mítica denominada Magonia, de la cual venían barcos sobre las nubes, y cuyos tripulantes se llevaban los frutos caídos por el granizo provocado por los tempestarios, a los que hacían valiosos regalos como muestra de agradecimiento.

Plerosque autem uidimus et audiuimus tanta dementia obrutos, tanta stultitia alienatos, ut credant et dicant quandam esse regionem, quę dicatur Magonia, ex qua naues ueniant in nubibus, in quibus fruges, quę grandinibus decidunt, et tempestatibus pereunt, uehantur in eandem regionem, ipsis uidelicet nautis aereis dantibus pretia tempestariis, et accipientibus frumenta uel ceteras fruges. ${ }^{8}$

Por primera vez descubrimos noticias específicas acerca de estos misteriosos individuos que se dedicaban a robar cosechas mediante recursos mágicos: contemplamos cómo actuaban y averigua-

6 Serm. seu instr. rust. [c. 969].

7 Determinados elementos internos (especialmente la epizootia del año 810 mencionada en el capítulo 6 de este breve tratado) permiten fechar el De grandine et tonitruis entre los años 815 y 817 , muy probablemente ca. 816, año de la consagración episcopal de Agobardo, lo que la convierte en la primera obra de este autor; véase Acker 1981, XXXVIII-XXXIX; Caruso 2018, 52 y 176; Jiménez 2018, 27-29. En lo que no hay acuerdo entre los diversos investigadores es en si la escribió siendo todavía corepíscopo (Cabaniss 1953, 100-101 y 121, n. 55; Heidecker 1995, 171) o poco después de su elección episcopal (Boshof 1969, 170).

8 Agobardus, De grand. et ton., 2 [p. 4]. 
mos cuál es el nombre de su tierra de origen, Magonia, aunque sorprendentemente Agobardo no menciona el gentilicio de estos personajes, que sin duda debían ser bien conocidos dentro del imaginario colectivo de sus parroquianos.

Algunos años después, Floro, diácono de la Iglesia de Lyon durante el episcopado de Agobardo, realizó una interesantísima alusión a esta tierra y a sus fabulosos habitantes en un escolio a un pasaje del tratado antimaniqueo Contra Faustum de Agustín de Hipona, conservado en el manuscrito Lyon B.M. 610 (f. 12v) 9 $^{9}$ Mediante una etimología errónea, Floro relaciona la doctrina de Manes con el fabuloso país de Maonia y sus habitantes maones.

$<\ldots>\mathrm{AB}(\ldots) \mathrm{MAN}(\mathrm{ICHAEORVM}) .<$ Nota $>$ quam insanam $<\mathrm{f}>$ abulam, insa $<\mathrm{n}>\mathrm{issimus}$ heresi<a $>$ rches Manés $<$ con>finxerit. Ex qua: stultissima uulgi opinio sumpta uidetur. Putantium terram quandam Maoniam, et ex ea Maones in caeli nauibus uenientes, et saepe inde ruentes, in grandine uel nebula fruges hominum auferre. Vnde et quosdam quos tempestarios uocant occidere soliti sunt, eosque ex ipso Mané Maones, et eorum terram Maoniam nuncupare uidentur. Nam et naues quasdam caelestes, et nauigantes in eis tenebrarum principes, $\left\langle\ldots . .^{11}\right.$

Se observan algunas importantes diferencias respecto al texto de Agobardo - que, por otro lado, Floro debía conocer bien-. Para empezar, los nombres: Floro ofrece la forma maones, que hemos visto en textos del siglo viII y que seguramente todavía debía resultar habitual en la diócesis lionesa durante la siguiente centuria. Además, Floro también expone el nombre de la mítica tierra de los maones, Maonia, que difiere en una letra de la forma presentada por Agobardo. Por otro lado, y a diferencia de Agobardo, para quien Magonia tan solo representaba un detalle que le servía para ilustrar la estupidez de la creencia en los tempestarios - y de ahí que la citara tan solo en una única ocasión en toda su obra-, Floro pone precisamente el acento en Maonia y en sus habitantes los maones para ponerlos en relación con Manes y su herejía, y exponer esta superstición como una muestra más del error de los maniqueos ${ }^{11}$. Por lo demás, la historia es la misma que lee-

9 El manuscrito Lyon, Bibliothèque Municipale, Ms. 610, cedido a la catedral de Lyon por el obispo Leidrado (fallecido en el 816), ha podido ser datado a partir del tipo de escritura a finales del siglo viı o inicios del Ix. Contiene exclusivamente el Contra Faustum de Agustín de Hipona - tratado dirigido contra el obispo maniqueo Fausto de Mileve-, y fue muy utilizado por Floro, quien le realizó numerosas anotaciones en sus márgenes. En un pasaje de esta obra (Augustinus, Contr. Faust., VI, 8 [p. 296]) explica el origen de la carne, según los maniqueos: cuando el Primer Hombre (del mito maniqueo) fabricó el mundo, lo hizo con los cuerpos de los príncipes de las tinieblas (de uno y otro sexo), a muchos de los cuales los encadenó a las fábricas celestes; cuando el cielo comenzó a girar, algunas hembras que estaban preñadas no pudieron soportar el vértigo y abortaron, y estos fetos abortivos (machos y hembras) cayeron a tierra, donde sobrevivieron, se aparearon y engendraron nuevas criaturas (que serían los actuales animales terrestres). Este pasaje suscitó un gran interés en Floro, quien decidió comentarlo. Y para ello añadió un paragraphus — un símbolo en forma de $\Gamma$ - justo antes de la palabra dicunt que abría el pasaje. La anotación es muy larga y ocupa casi todo el margen exterior del folio y finaliza en el inferior. Al respecto, véase Chambert-Protat 2014.

10 Florus, Schol. ad Aug. Contr. Faust., f. 12v. No existe una edición crítica de estos escolios de Floro a la obra de Agustín. Según nos consta, la glosa únicamente ha sido publicada por Pierre Chambert-Protat (2014) en el sitio web Florus de Lyon. Une bibliothèque et un auteur au milieu du neuvième siècle. Reproducimos, pues, la lectura del texto realizada por este autor.

11 Para Floro, la creencia en los maones llegados desde el cielo es una reminiscencia de las creencias de los maniqueos sobre los seres de carne caídos del cielo. Resulta una interpretación muy forzada basada en una etimología errónea. Como ha señalado Chambert-Protat (2014): «il n'y a rien de commun entre une histoire de pillards contemporains équipés de bateaux volants, et une cosmogonie recourant à des avortons tombés du ciel; la ressemblance entre le nom de Manès et celui des Maones n'est qu'une pure coüncidence». En el fondo se trataba de mostrar los puntos comunes entre 
mos en Agobardo: los maones llegan desde su tierra en navíos que vuelan sobre las nubes y roban a los hombres sus cosechas en medio del granizo y de la niebla. Los tempestarios, por su parte, tienen una presencia casi anecdótica en la glosa de Floro, quien nos dice de ellos que la gente acostumbraba a matarlos a causa de las rapacerías protagonizadas por los maones, a quienes el diácono incluso llega a calificar de "príncipes de las tinieblas".

\section{Interpretando el nombre de Magonia}

El nombre de Magonia y la historia asociada a él, a pesar de haber sido mencionados una única vez por Agobardo en su obra, resultan tan evocadores y poéticos que no han dejado de llamar la atención de numerosos investigadores que han deseado ofrecer una explicación al significado de este topónimo. Ya en las primeras décadas del siglo xIx, Jacob Grimm $(1835,367)$ consideró que el nombre de Magonia parecía tener su origen en un territorio donde se hablaba latín, y que podía relacionarse con el término magus, de modo que la tierra sería un "país mágico» (Zauberland). Unos treinta años más tarde, Pierre Chevallard $(1869,74)$ recogió esta interpretación y definió Magonia como el «pays des Magiciens». Esta identificación de Magonia con el «País de los magos» es la que más éxito ha tenido en la historiografía posterior. De este modo, lo observamos en numerosos autores de los siglos xx y xxI (a modo de ejemplo: Schmitt 1992, 60; Montesano 2008, 161; Caruso 2018, 66; Jiménez 2018, 94-95).

Sin embargo, diversos investigadores han buscado otras interpretaciones que resultaran también más o menos sugestivas. Michele C. Ferrari (2003, 169-170), aunque reconoce que la opción más fácil y convincente es contemplar Magonia como un derivado del vocablo magus y traducirla como "Tierra mágica», considera que tal vez se podría asociar con algo todavía más concreto. De este modo (Ferrari 2003, 170), especula con algunas posibilidades geográficas, como por ejemplo la Tierra de Magog, de donde, según las Escrituras (Ez 38, 9), su soberano Gog vendrá en el fin de los tiempos "como una tormenta" (quasi tempestas); el puerto de Majuma (o Maiuma, cerca de Gaza); o Puerto Mahón (Portus Magonis, en Menorca) ${ }^{12}$. E incluso Ferrari llega a recordar la magona o maona (del árabe ma’úna, 'ayuda mutua'), una sociedad mercantil de carácter financiero que algunas repúblicas italianas (especialmente Génova) pusieron en funcionamiento a finales de la Edad Media a fin de afrontar mejor grandes empresas comerciales marineras que de otro modo no hubieran podido llevar a cabo; sin embargo, en este caso, evidentemente, el principal escollo para poner este nombre en relación con la Magonia de Agobardo es el cronológico.

Por su parte, Henri Platelle (2004, 107 y 111, n. 11), sin llegar tampoco a descartar la hipótesis de "Tierra de magos», considera viable que se trate de la «Tierra de mahometanos».

Otros investigadores han intentado desligar el nombre de Magonia de un topónimo concreto y han querido buscar su origen en una casuística muy diversa. Ya a mediados del siglo xIx, Felix Liebrecht $(1856,62)$ relacionó Magonia con vocablos arcaizantes que servían para denominar el género de nube de tormenta en el antiguo alemán (Old High German) maganwetar —vocablo rela-

un error antiguo y otro coetáneo; de nuevo, en palabras de Chambert-Protat (2014): «assimiler les hérésies nouvelles aux anciennes, de manière que les Pères de l'Église aient déjà fourni, autrefois, le moyen de répondre aujourd'hui aux nouveaux hérétiques».
12 En este sentido, véase también Brodu 1995, quien defiende que hay que entender Magonia más como una dirección que como una localización concreta: los barcos que viajaban sobre las nubes vendrían de la dirección de Puerto Mahón. 
cionado con el del antiguo escandinavo vedrmegin ${ }^{13}$ _; el nombre de Magonia habría sido creado y latinizado a partir de la primera parte de maganwetar, el cual habría perdido su segunda mitad ${ }^{14}$.

Paul E. Dutton también reconoció que Magonia podía traducirse como una «Tierra mágica» (Dutton 2004, 174), pero con todo intentó ofrecer una nueva interpretación basada en una etimología diferente de Magonia. En este caso (Dutton 2004, 186), ya no estaría ligada a magus sino a mango y su variante magono ${ }^{15}$. En su origen, mango significaba 'mercader de esclavos', pero habida cuenta la mala fama de estos individuos, también acabó por señalar a todo aquel que «maquillaba» su mercancía con ánimo fraudulento, y, por tanto, se convirtió en un sinónimo de defraudador, falaz o mentiroso. Y es precisamente este el sentido que le otorga Dutton, quien, recordando que los «magonios» se llevaban de manera dolosa unos frutos que no eran suyos, estima que «the word Magonia may refer, then, not to a Magic Land, but to a Land of Unscrupulous Dealers (from mango or magono) in stolen crops».

Monica Blöcker $(1981,124)$ relacionó el nombre de Magonia con los maones de los que habló Pirminio y consideró que estos ladrones de cosechas se adecuaban al país de Magonia lingüística y fácticamente ( $\mathrm{Z} \mathrm{u}$ dem Land Magonia passen sprachlich und sachlich die maones, die Ernteräuber»). Karl Heidecker $(1995,179)$ también realizó la misma asociación y planteó la interesante cuestión acerca de si tal vez, bajo la creencia en los maones - los delincuentes itinerantes sospechosos de robar la cosecha mediante sus poderes demoníacos-, lo que se escondía en realidad era el miedo a las personas vagabundas de las que se pensaba que engañaban y robaban las cosechas para poder ganarse la vida. Igualmente en este sentido, Rob Meens (2012, 164-165) relacionó Magonia con los vocablos hemaones o ma(u)ones que se leen en diversas fuentes de los siglos vil y viII (y que hemos analizado en el apartado anterior) ${ }^{16}$.

13 Estos nombres ya habían sido estudiados por Jacob Grimm (1882, I, 332; 1883, II, 632). Véase también Ross 1998, 64.

14 Sabemos que en Italia, entre los siglos XIV y xV se utilizaba el término mago para referirse a un tipo de nube que traía la tormenta; además, las referencias que tenemos a ella se hallan siempre envueltas por un aura de superstición. De este modo, el fraile franciscano Niccolò da Poggibonsi — quien realizó una peregrinación a Tierra Santa entre 1345 y 1350 que él mismo describió en su Libro d'Oltramare - nos explica que en su regreso a Italia el barco en el que viajaba se vio sorprendido por una terrible tempestad, a propósito de la cual comenta: "vedemo in aria quello maledetto Spirito, lo quale noi chiamamo Macone» (Niccolò da Poggibonsi, Libro d'Oltramare, 262 [II, p. 226]). Aunque muchos investigadores han relacionado el nombre de Macone con el de Mahoma, estamos de acuerdo con Marina Montesano $(2008,161)$ en que realmente debemos vincularlo a Magonia. Menos de un siglo más tarde (entre 1430 y 1436), el célebre predicador Bernardino de Siena calificaba de absurdas las creencias medio paganas de los ma- rineros y recordaba como ejemplo que cuando algunos de ellos veían aparecer en el cielo un género de nube que ellos denominaban mago, desenvainaban sus espadas y las agitaban en el aire con la intención de amenazar y alejar a la nube; Bernardinus Sen., De idol. cult., 3, 2 [p. 113]: alii quoque, cum descendere uiderint quamdam nubem, quam quidam 'magonem' uocant, quae solet de mari haurire cum nauium periculo aquam, illam, euaginato ac uibrato ense, quibusdam coniurationibus praecidere quodammodo simulant. Véase Jiménez 2018, 44.

15 Acerca de magono como variante de mango, véase Latham 1965 (reimpr. 1983), 288.

16 Como estamos viendo, vocablos tales como hemaones o ma(u)ones corresponden a nombres que se usaban para señalar a la gente capaz de sustraer las cosechas a través de medios sobrenaturales. En consecuencia, debemos rechazar la interpretación de hemaones como una corrupción textual de la palabra daemones, como defienden: Banniard 1994, 176; Veyrard-Cosme 2003, 14, n. 3 («Texte corrompu: comprendre daemones»), Hauswald 2010, XXIII («Pseudo-Terminus maones, eine entstellte Wiedergabe von daemones»). 


\section{El ORIGEN DE UNA TIERRA MÍTICA}

En este último apartado vamos a intentar trazar el recorrido del nombre de Magonia hasta el que tal vez fue su más remoto origen. Estamos de acuerdo con Monica Blöcker en que debemos relacionar Magonia con el término maones; la glosa de Floro que hemos visto en el primer apartado no deja dudas al respecto. Como hemos podido comprobar, en el siglo viII la forma existente de referirse a los ladrones de cosechas por medios mágicos era con la palabra maones, la cual podía presentar la variante dialectal mauones. Estos vocablos derivaron con seguridad del término hemaones, que documentamos en el norte del Reino Franco, concretamente en la región de Picardía, en el siglo viI.

Durante estos siglos, tanto hemaones como ma(u)ones no parecen comportar ninguna connotación gentilicia, no aluden a ninguna patria de origen de los magos. Sencillamente, tan solo indican la pertenencia a una categoría de delincuentes, concretamente aquellos que se sirven de la magia para hacerse con el fruto del trabajo de los campesinos. Ahora bien, ¿de dónde procedía este nombre?

Aunque no resulta fácil determinar la procedencia de este vocablo, creemos que se trata de la vulgarización de la expresión Haemonias artes, es decir, las 'artes de Hemonia'. Hemonia es uno de los nombres con los que se designaba a Tesalia a partir del héroe epónimo Hemón, hijo de Pelasgo y padre de Tésalo (quien a su vez dio nombre a Tesalia) ${ }^{17}$. Y no hemos de olvidar la fama de patria de la magia de la que gozaba Tesalia en la Antigüedad ${ }^{18}$, por lo que hablar de las «artes de Hemonia» era tanto como decir las "artes mágicas». Así lo podemos ver, por ejemplo, en algunos pasajes de Ovidio ${ }^{19}$ y de Lucano ${ }^{20}$. En consecuencia, en su origen el término poseía una connotación topográfica que luego perdió con el tiempo.

En el siglo viI, en el norte del territorio franco, los hemaones eran mencionados ya desprovistos de toda evocación gentilicia; tan solo eran individuos entregados a la magia que se aprovechaban de sus poderes para apropiarse de los frutos y de las vendimias ajenas. El nombre se perpetuó en la siguiente centuria, ya convertido en maones, con su variante mauones, aunque ninguna de las fuentes de esta época nos dice cómo actuaban, más allá de que se dedicaban a arrebatar las cosechas de los campesinos. Tampoco nos hablan del lugar de donde procedían, y la impresión que obtenemos es que se trataba de individuos itinerantes que podían provenir de cualquier lugar.

17 Así puede observarse en Strabo, Geogr., IX, 5, 23 [p. 452].

18 En este sentido, podemos recordar el testimonio de Apuleius, Metam., II, 1 [p. 24]: reputansque me media Thessaliae loca tenere, qua artis magicae natiua cantamina totius orbis consono ore celebrentur. No olvidemos que el protagonista de la célebre novela de Apuleyo (escrita ca. 170 d.C.) viajaba a Tesalia por negocios, pero que lo hacía también con una gran alegría, puesto que, como él mismo nos narra, era un enamorado de todo aquello relacionado con la magia y la tierra a la que se dirigía resultaba pródiga en este tipo de prodigios.

19 Ouidius, Ars amat., II, 99 [p. 206]: fallitur, Haemonias siquis decurrit ad artes. En este pasaje del Ars amatoria (poema publicado ca. 2 d.C.), Ovidio critica a aquellos individuos que recurren a la magia y a los filtros amorosos como medios para ganarse el amor de una mujer.
20 Lucanus, De bell. ciu., VI, 485-486 [p. 150]: omne potens animal leti genitumque nocere / et pauet Haemonias et mortibus instruit artes. Estos versos del De bello ciuili (más popularmente conocido como Pharsalia, poema escrito entre el 61 y el 65 d.C., aproximadamente), se insieren en un popular pasaje que se desarrolla en el momento previo a la batalla crucial entre Pompeyo y Julio César: Sexto Pompeyo, el hijo de Pompeyo Magno, despreciando los métodos tradicionales vinculados con la religión para conocer la voluntad de los dioses, acude a Ericto, una de las hechiceras de Tesalia, a fin de averiguar cuál será el resultado del inminente enfrentamiento (Lucanus, De bell. ciu., VI, 413-830 [pp. 148-162]). Todo este largo episodio es rico en descripciones tanto de la celebridad de Tesalia como cuna de la magia en la Antigüedad como, de una manera más particular, de los métodos siniestros de Ericto a la hora de poner en práctica sus hechicerías. 
Ya en el siglo IX sabemos algo más sobre cómo eran percibidos en el territorio de Lyon gracias al testimonio de Agobardo: viajaban en barcos que volaban por encima de las nubes. El obispo incluso nos proporciona el nombre de su patria: Magonia. Este topónimo es un hápax y nos inclinamos a pensar que se trata de una creación de Agobardo. Podría pensarse que los campesinos hablaron a su prelado acerca de los maones y del peligro que representaban, aunque nada le dijeron acerca del nombre de su patria de origen; tan solo le comentaron que estos viajaban en barcos voladores. Agobardo consideró que, si viajaban en barcos, los aeronautas deberían proceder de algún lugar, por lo que creó el topónimo a partir de una asociación etimológica: como eran maones, debían proceder de Maonia, pero dado que este nombre no tenía sentido para él, lo cambió por Magonia, la Tierra de los magos. No obstante, creemos que la realidad pudo ser de otra manera.

Algunos años después de que Agobardo escribiera el De grandine et tonitruis, Floro recogió los elementos principales de esta superstición, incluidos los nombres pertinentes, en una glosa al Contra Faustum de Agustín de Hipona. Acerca de cómo llegó él hasta esta creencia, si lo hizo tan solo a través de la obra de Agobardo o a través del testimonio de los campesinos, debemos rechazar, por absurda, la idea de que Floro - quien poseía una cultura enciclopédica y tenía a su disposición la rica biblioteca episcopal de Lyon - no hubiera conocido el tratado de su obispo. Por otro lado, el hecho de que en su escolio recoja el nombre de los maones y de Maonia - en una forma diferente a la que había ofrecido Agobardo- nos lleva a pensar que también habría sido informado por los campesinos, quienes le habrían proporcionado tanto la historia como los nombres de los magos y de su patria.

Y esto nos conduce a formular la hipótesis acerca de cómo habría surgido el nombre de Magonia. Informado por sus feligreses acerca de todas estas fantasías — como posteriormente lo sería el diácono Floro-, Agobardo las habría incluido solo de manera parcial en su escrito: no introdujo el nombre de los maones, sino que se limitó a decir de ellos que llegaban hasta la diócesis de Lyon en barcos que volaban sobre las nubes con el fin de llevarse los frutos caídos por el granizo que a su vez había sido provocado por los tempestarios; sí que incluyó, en cambio, el nombre de su tierra de origen. Pero resulta muy probable que cuando oyó que los campesinos le decían que se llamaba Maonia, Agobardo pensase que este nombre no tenía ningún tipo de sentido (ital vez porque estimó que los rústicos no lo pronunciaban bien?), de modo que decidiría modificarlo a fin de proporcionarle algún significado lógico. Y teniendo en cuenta que los maones eran magos, Agobardo creyó que su patria debía denominarse Magonia, es decir, «Tierra de los magos», y así lo consignó en su obra.

En consecuencia, este nombre tuvo una historia azarosa. Tuvo su origen más remoto en un topónimo real - Hemonia (o Tesalia), la cuna de la magia-, para pasar luego a perder este componente gentilicio - de tal modo que los hemaones o maones serían tan solo una categoría más de magos-y recuperarlo en el siglo IX con Agobardo, mediante la creación del nombre de una tierra ya absolutamente mítica y fabulosa, Magonia, el lugar del que venían unos navíos volando por encima de las nubes.

\section{FUENTES}

Agobardus, De grand(ine) et ton(itruis), ed. L. van Acker, CCCM 52, Turnhout: Brepols, 1981, 3-15.

Apuleius, Metam(orphoses), ed. R. Helm, Apulei opera quae supersunt, I, Bibliotheca Scriptorum Graecorum et Romanorum Teubneriana, Leipzig: B. G. Teubner, 1907.

Augustinus, Contr(a) Faust(um), ed. J. Zycha, CSEL 25, Wien: F. Tempsky, 1891, 249-797. 
Augustinus, De ciu(itate) Dei, ed. B. Dombart y A. Kalb, CCSL 47-48, Turnhout: Brepols, 1955.

Bernardinus Sen(ensis), De idol(atriae) cult(u) (Quadragesimale de christiana religione, sermo X), ed. Patres Collegii S. Bonauenturae, S. Bernardini Senensis Ordinis Fratrum Minorum Opera Omnia, I, Quaracchi (Firenze): Collegii S. Bonaventure, 1950, 105-118.

Florus, Schol(ia) ad Aug(ustini) Contr(a) Faust(um), ed. P. Chambert-Protat, "Florus de Lyon et les extraterrestres», en: Florus de Lyon. Une bibliothèque et un auteur au milieu du neuvième siècle, 2014 (disponible en: https://florus.hypotheses.org/292) [fecha de consulta: 20/03/2020].

Isidorus, Etym(ologiae), ed. W. M. Lindsay, Oxford: Clarendon, 1911.

Lucanus, De bell(o) ciu(ili) (Pharsalia), ed. D. R. Shackleton Bailey, Bibliotheca Scriptorum Graecorum et Romanorum Teubneriana, Berlin-New York: Walter de Gruyter, 2009.

Niccolò da Poggibonsi, Libro d'Oltramare, ed. A. Bacchi della Lega, Libro d'Oltramare di Fra Niccolò da Poggibonsi, Bologna: Gaetano Romagnoli, 1881, 2 vols.

Ouidius, Ars amat(oria), ed. R. Ehwald, Ouidii opera, I: Amores, Epistulae, Medicamina faciei femineae, Ars amatoria, Remedia amoris, Bibliotheca Scriptorum Graecorum et Romanorum Teubneriana, Leipzig: B. G. Teubner, 1888, 183-246.

Pirminius, Scaraps(us), ed. E. Hauswald, MGH qgm 25, Hannover: Hahnsche Buchhandlung, 2010.

Serm(o) seu instr(uctio) rust(icorum), ed. A. Hamman, PLS 4, Paris: Garnier, 1968, 967-969.

Strabo, Geogr(aphica), ed. H. L. Jones, The Geography of Strabo, IV, The Loeb Classical Library, LondonCambridge MASS.: William Heinemann LTD-Harvard University Press, 1927 (reimpr. 1954).

Vit(a) Richar(ii) prim(igenia), ed. B. Krusch, MGH srm 7, Hannover-Leipzig: Societas Aperiendis Fontibus Rerum Germanicarum Medii Aeui, 1920, 438-453.

\section{BiBLIOGRAFÍA}

ACKer, L. van, 1981, Agobardi Lugdunensis opera omnia [CCCM 52], Turnhout: Brepols.

Andrés Sanz, M. A., 2010, «Pirmenio», en: C. Codoñer (coord.), La Hispania visigótica y mozárabe. Dos épocas en su literatura [Obras de referencia 28], Salamanca: Universidad de Salamanca-Universidad de Extremadura, 265-267.

Banniard, M., 1994, «Seuils et frontières langagières dans la Francia romane du viII ${ }^{\mathrm{e}}$ siècle», en: J. Jarnut, U. Nonn, M. Richter (eds.), Karl Martell in seiner Zeit, Sigmaringen: Thorbecke, 171-191.

BLÖCKer, M., 1981, «Wetterzauber: Zu einem Glaubenskomplex des frühen Mittelalters», Francia 9, 117 131 (https://doi.org/10.11588/fr.1981.0.50894).

Boshof, E., 1969, Erzbischof Agobard von Lyon. Leben und Werk [Kölner historische Abhandlungen 17], Köln-Wien: Böhlau Verlag.

Brodu, J.-L., 1995, «Magonia: a re-evaluation», Fortean Studies 2, 198-215.

Cabaniss, J. A., 1953, Agobard of Lyons. Churchman and Critic, Syracuse: Syracuse University Press.

Caruso, P., 2018, I trattati di Agobardo di Lione contro le superstizioni. Introduzione, testo latino, traduzione italiana e note [Quaderni dell'Accademia Pontaniana 64], Napoli: Accademia Pontaniana.

Сhambert-Рвотат, P., 2014, "Florus de Lyon et les extra-terrestres», en: Florus de Lyon. Une bibliothèque et un auteur au milieu du neuvième siècle (disponible en: https://florus.hypotheses.org/292) [fecha de consulta: 20/03/2020].

Chevallard, P., 1869, L'Église et l'état en France au neuvième siècle: Saint Agobard, archevèque de Lyon. Sa vie et ses écrits, Lyon: P. N. Josserand.

Du Cange, C., 1884, «Dusii», en Glossarium Mediae et Infimae Latinitatis, III, Niort: L. Favre, 219-220.

Dutton, P. E., 2004, "Thunder and Hail over the Carolingian Countryside», Charlemagne's Mustache and other Cultural Clusters of a Dark Age [The New Middle Ages], New York: Palgrave Macmillan, 169-188 (https://doi.org/10.1007/978-1-137-06228-4_7).

Ferrari, M. C., 2003, "Aura leuatitia. Naturbeherrschung und Naturexegese im Frühmittelalter», en: P. Dilg (ed.), Natur im Mittelalter. Konzeptionem -Erfahrungen - Wirkungen (Akten des 9. Symposiums 
des Mediävistenverbandes, Marburg, 14.-17. März 2001), Berlin: De Gruyter, 163-177 (https://doi. org/10.1524/9783050050065.163).

Grimm, J., 1835, Deutsche Mythologie, Göttingen: Dieterichschen Buchhandlung.

Grimm, J., 1882, Teutonic Mythology, I, London: George Bell and Sons (trad. J. S. Stallybrass: Deutsche Mythologie, Berlin: F. Dümmler, $\left.1875^{4}\right)$.

Grimm, J., 1883, Teutonic Mythology, II, London: George Bell and Sons (trad. J. S. Stallybrass: Deutsche Mythologie, Berlin: F. Dümmler, 1877 ${ }^{4}$.

Hauswald, E., 2010, Pirmin. Scarapsus [MGH qgm 25], Hannover: Hahnsche Buchhandlung.

Heidecker, K., 1995, "Agobard en de onweermakers. Magie en rationaliteit in de vroege Middeleeuwen», en: M. Mostert, A. Demyttenaere (eds.), De betovering van het middeleeuwse christendom. Studies over ritueel en magie in de Middeleeuwen [Amsterdamse historische reeks. Grote serie 22.], Hilversum: Verloren, 171-194.

Jiménez, J. A., 2018, Agobardo de Lyon. Sobre el granizo y los truenos. Introducción, traducción y comentarios [Libros del tiempo 362], Madrid: ed. Siruela.

Judic, B., 1998, «La tradition de Grégoire le Grand dans l'idéologie politique carolingienne», en: R. Le Jan (ed.), La royauté et les élites dans l'Europe carolingienne (du début du IX'e siècle aux environs de 920) [Histoire et littérature du Septentrion (IRHiS) 17], Villeneuve d'Ascq: Centre d'histoire de l'Europe du Nord Ouest, 17-57 (también publicado en formato de libro electrónico, disponible en: https://books. openedition.org/irhis/2552) [fecha de consulta: 16/03/2020].

Latham, R. E., 1965 (reimpr. 1983), Revised Medieval Latin Word-List from British and Irish Sources, London: Oxford University Press.

Levison, W., 1946, England and the Continent in the Eighth Century, Oxford: Clarendon Press.

Liebrecht, F., 1856, Des Gervasius von Tilbury Otia Imperialia, Hannover: Carl Rümpler.

MeEns, R., 2012, "Thunder over Lyon: Agobard, the Tempestarii and Christianity», en: C. Steel, J. Marenbon, W. Verbeke (eds.), Paganism in the Middle Ages. Threat and Fascination [Mediaevalia Lovaniensia. Series I, Studia 43], Leuven: Leuven University Press, 157-166.

Montesano, M., 2008, "La circolazione di motivi stregonici tra folklore e cultura scritta», en: D. Corsi, M. Duni (ed.), "Non lasciar vivere la malefica». Le streghe nei trattati e nei processi (secoli XIV-XVII) [Biblioteca di storia 7], Firenze: Firenze University Press, 155-166 (https://doi.org/10.1400/113986).

Platelle, H., 2004, «Agobard, évêque de Lyon (†840). Les soucoupes volantes, les convulsionnaires», en: H. Platelle (ed.), Présence de l'au-delà. Une vision medieval du monde [Histoire et civilisations 898], Villeneuve d'Ascq: Presses Universitaires du Septentrion, 105-112.

Poncelet, A., 1903, "La plus ancienne vie de S. Riquier», Analecta Bollandiana 22, 173-194 (https://doi. org/10.1484/J.ABOL.4.00487).

Ross, M., 1998, "Anchors in a Three-Decker World», Folklore 109, 63-75 (https://doi.org/10.1080/00155 87X.1998.9715962).

Schmitt, J.-C., 1992, Historia de la superstición [Drakontos], Barcelona: Crítica (trad. T. Clavel: Les «Superstitions», Paris: Éditions du Seuil, 1988).

Veyrard-Cosme, C., 2003, L'oeuvre hagiographique en prose d'Alcuin. Vitae Willibrordi, Vedasti, Richarii. Édition, traduction, études narratologiques [Per verba: testi mediolatini con traduzione 21], Firenze: SISMEL Edizioni del Galluzzo. 